\title{
La relación del martirio de los santos del Caaró escrita por el P. Diego de Boroa en 1629
}

The relation of the martyrdom of the saints of the Caaró

written by Fr. Diego de Boroa in 1629

\section{Martín Barrabino*}

\section{Nota introductoria}

Este trabajo es uno más de la serie de obras inéditas del P. Boroa, especialmente las inclinadas al género biográfico, que realizamos dentro del "Programa Antiguos Jesuitas en Iberoamérica". Un género ampliamente desarrollado entre los jesuitas que no siempre tuvo como objetivo ser publicado y que incluso puede involucrarse en otras tipologías como cartas de edificación que escriben testigos a superiores inmediatos, y otras que de éstos van dirigidas a autoridades civiles e incluso a Roma, o simplemente a amigos o conocidos. Suman a ellas los obituarios insertos en las Cartas Anuas, que tienen como base de información aquellos textos (Page, 2014, pp. 2-22).

San Roque González de Santa Cruz (Asunción del Paraguay, 1576 - Caibaté, 15 de noviembre de 1628), canonizado por Juan Pablo II en 1988, fue una figura emblemática en las nacientes misiones del Paraguay. Entre una copiosa bibliografía edita e inédita sobre los mártires, escribió de ellos el P. Diego de Boroa. Nos exime el P. Storni (1976, pp. 318-348) de un análisis exhaustivo de los escritos sobre los mártires, de quienes se ocupó detalladamente.

Bien conocido era el mártir de su biógrafo, quien junto al P. Lorenzana se encargaron de imprimir el catecismo y sermones del Concilio Limense, en lenguas guaycurú y mbayá, traducido por el P. Roque. Además, junto al P. Boroa fundaron la reducción de Encarnación de Itapúa en 1615, donde este último permanecerá como superior de las

* CIECS-CONICET/UNC. Email: mbarrabino@ hotmail.com

201 Martín Barrabino. La relación del martirio de los santos del Caaró escrita por el ... 201-206. 
misiones hasta que en 1626 lo reemplaza el P. Roque y el P. Boroa pasa como rector del colegio de Asunción, tiempo en el cual sucedió la muerte de su compañero, en un difícil contexto donde, desde otro frente, los bandeirantes comenzaban sus estragos en las reducciones del Guayrá.

Del martirio escribieron varios y prestigiosos historiadores, entre ellos el P. José María Blanco que toma directamente su información de los documentos del proceso apostólico también publicado. Mientras que las obras de Teschauer y Jaeger en lengua portuguesa se suman para constituir una buena base de conocimiento. Pero las raíces historiográficas se remontan a aquellos días del martirio. Efectivamente la primera noticia que conocemos de las muertes, la brinda el P. Tomás de Ureña por la carta que le envió desde Encarnación de Itapúa al P. Juan de Cereceda, rector del colegio de Santa $\mathrm{Fe}$, a solo cinco días de producido el martirio ${ }^{1}$. De inmediato el P. Lorenzana informó al provincial Vázquez Trujillo la recepción de las reliquias de los tres sacerdotes. Mientras que el futuro mártir del Itatín, el sevillano P. Pedro Romero relató el suceso al gobernador Hernandarias en el mismo mes de diciembre ${ }^{2}$. La noticia no solo fue informada por los jesuitas sino que a su vez hubo textos escritos por otras personas, como la relación que el capitán Manuel Cabral le elevó al gobernador de Buenos Aires Francisco de Céspedes, también de fines de 1628. Al igual que el testimonio de Juan Ramos de Vera en los inicios del proceso sobre el martirio.

Llegamos al mes de enero siguiente cuando el día 24 firma la carta que presentamos el P. Boroa, que se la dirigió al P. Julián López, a la sazón procurador de los jesuitas en Indias. Carta que publicó el P. Pastells (1912, pp. 425-426), aunque no como un documento del Archivo de Indias sino como nota a final de página sin citar la procedencia. También la publicó el mencionado P. Blanco y en las actas del Sacra Congregatio Rituum de 1932.

Si bien se conoce una carta que envió el provincial Francisco Vázquez Trujillo al general contándole del martirio, pero sobre todo de su viaje a las misiones, parece ser que a Roma llegaron varias cartas, pues el general informó que recibió la noticia del martirio a los PP. Oreggi, Lorenzana, Boroa, Pastor y al propio provincial (Storni, 1976, p. 327).

Precisamente en el mes de octubre se elevó a Roma el proceso ante el ordina-

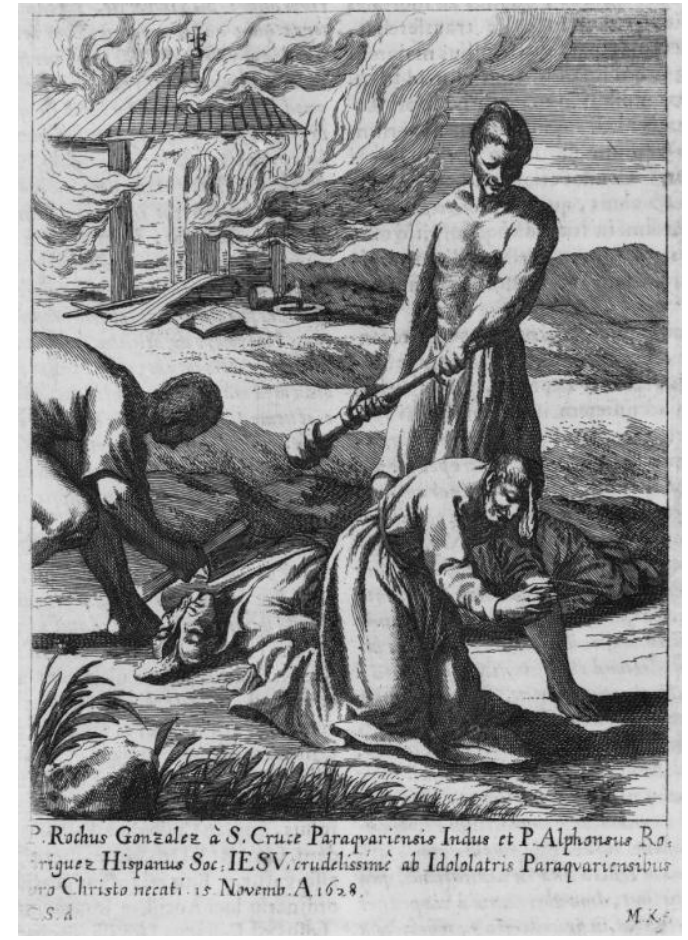

El martirio en la representación del grabador alemán Melchior Küsel publicado en el libro de Tanner de 1675.

\footnotetext{
${ }^{1}$ Esta carta se incluyó en la Anua de 1628 del provincial Mastrilli Durán, publicada por primera vez en 1636 y luego 1638. El P. Leonhardt lo hizo en 1929, quien a su vez la publicó en un trabajo sobre los mártires (1928, pp. 193-208).

${ }^{2}$ Esta relación fue publicada por el P. Blanco en 1929 y en las actas de la Sacra Congregatio Rituum de 1932.
} 
rio, donde se compilaron varios testimonios como el de fray Luis de Bolaños OFM, del mencionado Cabral, etc.

En tanto que en el ARSI se encuentran dos relaciones anónimas que presiden la del P. José Oreggi, escrita en italiano y que cronológicamente dará inicio a las primeras publicaciones. En este sentido la pionera es la madrileña del procurador general de las Indias P. Francisco Crespo ${ }^{3}$ (1630) con varias ediciones ${ }^{4}$, como a su vez la tuvo el libro del P. Juan Bautista Ferrufino aparecido por primera vez en Sevilla en 1633.

El P. Boroa volvió a hacer referencia al martirio en su Anua de 1637 y en otras cartas. También lo hizo Ruiz de Montoya en 1639 y Nieremberg en ese mismo año y en 1644, quien conoció a los PP. Castillo y Rodríguez, específicamente con el primero hicieron juntos el noviciado en Madrid. Varios años después escribe de los mártires el P. Del Techo, tanto en su obra clásica de 1673, como en las Decades, publicadas recién en 1759. Dejamos aquí, pues sería extendernos demasiado con la nutrida bibliografía que advertimos al principio.

La carta del P. Boroa no pretende ser una rigurosa biografía como la que escribió el P. Lorenzana, simplemente describió los sucesos sobre la muerte, en su condición de rector del colegio de Asunción. Aunque sobre todo por su experiencia misional y especial contacto que tuvo con los mártires. El texto es una copia que incluso se agregó al final que llegó luego una relación impresa más copiosa desde Madrid, indudablemente la del P. Crespo. Pero creemos que la presente es una copia reducida pues el P. Del Techo (2005) se refería a ella como "larga y bien escrita historia", en tanto el P. Furlong (1944) también da cuenta de esta obra de Boroa: "tan extensa y detallada que constituía un grueso volumen distribuido en cuatro libros", pero no cita dónde se encuentra ese libro y evidentemente no es esta.

Archivo Provincial de Toledo (Hoy Archivo de la provincia jesuítica de España). Estante 2, Caja 87 Paraguay (II) 14 Martirio de los PP. Roque Gonzalez de Santa Cruz, Alonso Rodriguez y Juan del Castillo. Relación del P. Diego de Boroa (1628) (Lg 1137.6)

Relaçion del martirio de los tres Padres Roque de Santa Cruz, alonso Rodrigues y el Padre Juan del Castillo, muertos en la provincia del paraguay en uruguay, escrita por el Padre Diego de boroa, Rector que fue de buenos ayres al Padre Julian Lopez procurador general de las indias, fecha en 24 de enero de 1629 y llego a sevilla un año después.

Yo a casi dos meses que sali del Colegio, aestas residencias y misiones del Urugay la causa demi venida fue lamuerte y martirio de los santos Padres Roque desanta cruz, natural de la asunción del Paraguay superior destas misiones, y el primero que

\footnotetext{
${ }^{3}$ Sobre aspectos biográficos y obra del P. Francisco Crespo ver Toral (1978, pp. 59-62).

${ }^{4}$ El laborioso P. Storni confiesa que no pudo encontrar la edición de Madrid, ni la de Lille del mismo año, la latina de Viena de 1631 y que pudo trabajar solo con la de Nápoles de 1632 que publicó Lazaro Scoriggio, además de contar con una versión manuscrita italiana del ARSI. Nosotros, y gracias a los avances bibliográficos que se presentan en distintos repositorios en la web, dimos con esa primera edición del libro que se encuentra en la Biblioteca Complutense de Madrid de 34 páginas.
} 
predico el evangelio enesta provincia del Uruguay, confirmandolo consu sangre, varon de conocidissima santidad fue martirisado consu compañero el Padre Alonso Rodriguez, natural de zamora, y al $3^{\circ}$ dia $^{5}$ en otro lugar ocho leguas de alli el Padre Juan del castillo, natural de belmonte, todos tres de gran virtud, la causa fue lapredicacion del santo evangelio y nueuas costumbres, el reduzír los indios gentiles para que fuesen Xrisptianos fue el aborrecimiento al santo baptismo, y el recelo que con el evangelio avian deperder un gran monton de mugeres, un cacique hechizero y falso dios que les mando matar, los dos primeros los mato otro cagique por mandado suyo y al Padre Juan, el mismo le hizo matar ensu pueblo, y brevemente paso asi remitiendome ala mas larga relación del anua ${ }^{6}$.

A primero de noviembre del año pasado de 1628 llego el Santo Padre Roque que era superior con el Padre Alonso Rodriguez aun pueblo de infieles o por mejor dezír, a un campo rodeado de montes y poblesuelos, para hazer residencia llamado Caro. Con gusto, delos caziques y al parezer de todos, hizo la iglesia y choza pajiza, y al día 15 quiso lebantar un horcon con una campana, y ya la gente dela traycion avisada del hechizero que se hazia dios estaba apunto, abajose el Santo Padre Roque para atar la soga a la Campana y llego uno por detras y díole con una porra de piedra en la cabeza, cayo y luego le dieron tantos, que le hicieron pedasos menudos la cabesa y la cara arrastraronle, metieronle en la iglesia ya muerto, salio el Padre Alonso Rodriguez al ruydo y como vio el Padre muerto, recojiose a casa y le iban aporreando con la soga dela campana salio a la puerta y allí le dieron con porras y palos tantos golpes que le mataron y partieron por medio y llevaron a quemar ala iglesita con el Santo Padre Roque y luego derribaron la cruz, hizieron pedasos las imagenes y profanaron los ornamentos sagrados.

No contentos con esto, el dia siguiente volvieron a ver los cuerpos y visto que no estaban bien quemados amontonaron alli palos y el corason del Santo Padre Roque al que avian avierto el pecho, les hablo y les dijo: aveis muerto a quien os amaba y queria pero mi cuerpo solo aveis muerto, que mi alma esta enel cielo y bolvere a ayudaros que muchos trabajos os an de venir por ocasión de mi muerte, ellos en lugar de compungirse se enojaron, y sacaron el corason y le atravesaron con una flecha y le echaron en el fuego pero el que pudo hazerle hablar, pudo escaparle de la fuerza del fuego, porque el corason no se quemo, yo le e tenido enestas manos, enjugose del jugo con el fuego pero no se quemo ni hizo carbon sino que quedo entero y despues se hallo entre las cenizas.

Hecho esto, dieron aviso al hechisero y falso dios ñeza ${ }^{7}$ elqual hizo gran fiesta y se emplumo y hizo todas sus ceremonias para invocar al demonio y les mando matar al Padre Juan del castillo que avia solos tres meses que estaba entre ellos, lo qual hizieron estando el buen Padre rezando vísperas alos 17 del mismo mes dos dias despues dela muerte delos dos, abrazaronle a traycion maniataronle derribaronle abofetearonle con baldones arrastraronle vivo y le iban flechando y dando golpes y quitandole apedazos los vestidos llevaronle tres cuartos de legua por una tierra aspera abajo por dos montes y dos arroyos y a pedradas y palos le mataron y luego le quemaron y la iglesia derribaron

\footnotetext{
${ }^{5}$ González y Rodríguez mueren el 15 de noviembre y Castillo en Yjuhi (Rio Grande do Sul) el 17, es decir dos días después (Storni, 1980, p. 59), aunque el P. Boroa más adelante aclara el día 17.

${ }^{6}$ Se refiere a la Carta Anua de 1628 mencionada.

${ }^{7}$ El hechicero y cacique de Ijuí, Nezú, fue el que decidió la muerte de los misioneros de la región, porque se oponían a la poligamia y con su creciente influencia, en el marco de una rebelión de grandes proporciones (Melo de Oliviera, 2011, pp. 109-138).
} 
la cruz ettcetera y luego fueron tres leguas de alli a matar al Padre Alonso de aragon ${ }^{8} \mathrm{y}$ al Padre francisco clavijo ${ }^{9}$, pero los indios estando ya a tiro de piedra los enemigos de la fe escon[roto: dieron] del Caro quisieron matar al Padre Pedro Romero, al qual defendieron los fieles porque su intento era acabar con todos los Padres y la fee para vivir a sus anchuras sin rezelo pero el Señor les a atajado los pasos porque sabiendo los indios cristianos y reducidos sus intentos juntaron mas de mil indios y los cogieron sin perdida ninguna en una batalla que ellos mismos presentaron entregadolos al Señor y se ira quietando esto y ira adelante, pues abra 8 dias que fueron los indios infieles deste rio arriba a llamarnos que le vengamos a hazer residencia, y yo vine 4 dias ha y me han resebido con mucho amor. De Uruguay, enero 24 de 1629. Diego de Boroa (rubricado), y a continuación se lee: Vino relasion impresa mas copiosa de madrid, esta en un tomo de $8 .^{\circ}$

\section{Referencias}

Blanco, J. M. (1929). Historia documentada de los PP. Roque González, Alonso Rodríguez y Juan del Castillo. Buenos Aires: Amorrortu.

Crespo, F. (1630). Relacion del glorioso martyrio de los Padres Roque Gonçalez, Alfonso Rodriguez, u Iuan del Castillo de la Compañia de Iesus, que por la predicación del santo Evangelio, y defensa de nuestra santa Fé Catolica, murieron a manos de los Indios infieles de la Prouincia del Vruay, el mes de Nouiembre de 1628 años. Madrid: Por Andres de Parra. Recuperado de: https://books.googleusercontent.com/books/content?req=AKW5Qac3VTjQhwbf xyx7QBogab79oJOZDxki7dJAMtUvQ2XXGXhctEwpXP2SlhzGP4r9KHgtuq11P_WGNyHDVJDAz80_5be09ftdEmLgWs5UUjQI_Nj5b65Q1mWwKrDDi 3bB0NLtrbJ6B6QvDAR2kNwFwghKP5uZ52qdH44yicLakXDHhy57jHMWoN SBBrR5uM4qeiArmHAPxf_evQTi7X8BDUkx9Ucp2RfKNv8vafBRpKQaPR4dbVnikSk7ZtO1HF7Nn87g56JXVfz3S0F2DvZeejFWLVENr pJqO098pxEOWMzguBTPM

Furlong SI. G. 1944. Historia del Colegio del Salvador y de sus irradiaciones culturales y espirituales en la ciudad de Buenos Aires 1617-1943. T. I. Colegio del Salvador, Buenos Aires.

Leonhardt, C. (1928). El P. Roque González y compañeros, mártires de la Compañía de Jesús, según documentos contemporáneos (1628 - 15 y 17 de noviembre - 1928). Estudios, 36, pp. 193-208.

Melo de Oliviera (2011). A rebelião de Nezú: em defesa de "su antiguo modo de vida" (Pirapó, Província Jesuítica do Paraguai, 1628). Anos 90, Porto Alegre, 18 (34) pp. 109-138.

\footnotetext{
${ }^{8}$ Se refiere al P. D’Aragona (1585-1629), nacido en Nápoles y fallecido en Asunción. Llegó a Buenos Aires en 1617, profesando sus ñultimos votos rn Concepción en 1621 (Storni, 1980, p. 76)..

${ }^{9}$ El P. Clavijo (1599-1644), nació en Córdoba, España y falleció en la reducción de Corpus en Misiones. Llegó a Buenos Aires en 1628 (Storni, 1980, p. 66)
} 
Page, C. A. (2014). El desarrollo del género biográfico entre los jesuitas del Paraguay antes de la expulsión de España, História, Histórias. 2 (4). Revista do Programa de Pós-graduação em História da Universidade de Brasília, Brasil, pp. 5-22.

Pastells, P. (1912). Historia de la Compañía de Jesús en la Provincia del Paraguay (Argentina, Paraguay, Uruguay, Perú, Bolivia y Brasil), según los documentos originales del Archivo General de Indias. Madrid: Librería General de Victoriano Suárez.

Sacra Congregatio Rituum. Bonaeren . ... Super dubio: An sit signanda Commissio introductionis causae, 13.7.1932. Acta Apostolicae Sedis, 24 (Romae 1932).

Storni, H. (1976). Documentación y bibliografía sobre los beatos mártires rioplatenses. Archivum Historicum Societatis Iesu. 1 (45). Roma, pp. 318-348.

Toral, E. (1978). Francisco Crespo, procurador general de las Indias. Boletín del Instituto de Estudios Giennenses. 24 (95), pp. 59-62. 